\title{
WAREHOUSING IN FINNISH AND SWEDISH COMPANIES: STATE OF OPERATING ENVIRONMENT DURING PERIOD OF 2006-2012
}

\author{
Olli-Pekka Hilmola \\ Lappeenranta University of Technology \\ Department of Industrial Management, Kouvola Unit \\ Prikaatintie 9, 45100 Kouvola, Finland \\ Fax: +358 5344 4009. E-mail: olli-pekka.hilmola@lut.fi,www.kouvola.lut.fi.
}

\begin{abstract}
Despite all the efforts of Just in Time philosophy, companies are still required to run numerous warehouses to accomplish distribution management objectives, and match supply network to this activity. In this research is being reported state of the warehousing practices in the largest Finnish and Swedish companies relying on longitudinal data gained through five different surveys. Research findings show that together these two countries are still on the cost pressure with respect of transportation. Also companies in these two northern countries are still using mostly semi-trailers on their distribution transportation. However, some evidence is on place that containers are taking higher role. Interestingly, most of the warehouses of these two countries report to be located in the countries of the Baltic Sea Region, finding which is rather striking as we have given so much effort on economical integration of this region in the recent decades. Finnish companies seem to hold much larger interest on Central and Eastern European Countries warehousing. Size of warehouses is likely to increase a little bit, and units located in other continents are much smaller.
\end{abstract}

Keywords: warehousing, transportation, Finland, Sweden, Geographical Coverage, CEEC

\section{Introduction}

Importance of warehousing is difficult to illustrate through statistics, since manufacturing and retail companies are still having this activity at their own disposal, and only partly these operations have been outsourced (world-wide outsourcing is still progressing trend, like [1,2]). Based on European wide transportation statistics, warehousing companies (have named this as their branch) employ second largest amount of people in the sector, led by road transportation (freight). However, based on numerous studies, outsourcing levels in warehousing work itself are not extremely high (opposite to transportation, where it is at level of 90\%). Based on Cap Gemini [3] study outsourced level in Europe is 68\%, and later Hilmola \& Tan [4] illustrated that in Finland and Sweden this is close to 50\%. Large-scale survey completed in Finland recently illustrated that warehousing outsourcing level could be in reality as low as $25-30 \%$ [5].

In regional comparison countries of interest in this study, Finland and Sweden are following, e.g., in relative terms Germany, Estonia and Latvia in warehousing sector employment. Interestingly, in Finland during years 2008 and 2009 warehouses employed roughly as many people in this sector as what is the situation in Latvia. In turn Swedish warehousing employment is at the level of all The Baltic States together. Germany with strong manufacturing industry representation, central position in Europe as well as large internal consumer markets lifts it to class of its own with warehousing branch. More than a half million people are working in companies having main activity in here. Also worth to mention is that one of the worst economic crises in decades taken place in year 2009 did not affect that greatly warehousing employment in our two year observation period - decline was roughly 2.5-3.6\% (in EU12, 15 and 27). This might be due to the reason that inventory levels have been streamlined with Just In Time and Lean systems, and therefore warehousing follows end demand closely, and some volume is still left at warehouses (in both directions, incoming and outgoing), even if sudden collapse is experienced (and this decline is not further fostered by large inventories at hand). It should also be noted that amount of warehouses and $\mathrm{m}^{2}$ are still on long-term growth path, even if manufacturing is in turn at the structural and long-term decline (they are soon intercepting each other e.g., in UK, [20]). 
Table 1. Warehousing employment ('000) in European Union during years 2008 and 2009. Source: European Union [6,7]

2009

Region/country Employees \% from total

\begin{tabular}{|l|r|r|}
\hline \hline EU27 & 2379.3 & $22.5 \%$ \\
\hline EU15 & 2010.0 & $23.6 \%$ \\
\hline EU12 & 369.3 & $17.8 \%$ \\
\hline Germany & 548.5 & $29.7 \%$ \\
\hline Estonia & 10.3 & $27.3 \%$ \\
\hline Latvia & 24.6 & $34.9 \%$ \\
\hline Lithuania & 14.1 & $15.4 \%$ \\
\hline Finland & 28.1 & $18.3 \%$ \\
\hline Sweden & 49.0 & $18.9 \%$ \\
\hline
\end{tabular}

2008

Region/country Employees \% from total

\begin{tabular}{|l|r|r|}
\hline \hline EU27 & 2463.9 & $27.1 \%$ \\
\hline EU15 & 2084.7 & $29.1 \%$ \\
\hline EU12 & 379.2 & $19.7 \%$ \\
\hline Germany & 566.1 & $39.5 \%$ \\
\hline Estonia & 10.5 & $28.8 \%$ \\
\hline Latvia & 26.1 & $37.1 \%$ \\
\hline Lithuania & 15.4 & $16.8 \%$ \\
\hline Finland & 27.4 & $22.3 \%$ \\
\hline Sweden & 53.0 & $23.7 \%$ \\
\hline
\end{tabular}

During the last decades (mostly after the oil crisis of the 70's), main tendency in warehousing has been centralization [8-11, 21]. Many factors have enabled this, but mostly it is accountable to cheap oil (during the 80's and 90's), deregulation in different sub-sectors of transportation logistics, free trade movement around the world (World Trade Organization) and over capacity of transportation sector (caused by different factors). So, basically in numerous industries it has been beneficial to shift inventories and warehouses on wheels (or sea vessels or airplanes; e.g., [12]), and reduce drastically distribution network nodes. This has enabled short response (implemented typically with road and air) and considerably lower amount of inventory investments. Again inventory reduction and centralization on very few locations, to say like in Europe, has increased the ability for companies to introduce newer models faster, recover from product quality problems easier and enable service and customisation based on orders $[13,14]$. However, with ultra low interest rates (implemented after credit crisis), extremely dear oil, product flows coming around the world for own end products, and increasing pressures to respond on environmental demands (and to be able to lower amount of transport, and particularly increase fill-rates) have changed this ongoing centralization wave. Also emerging countries in Europe, outside free trade area, have required, together with earlier mentioned factors, that companies need to have more warehouses $[15,16,19]$. So, current tendency is a bit diverting from earlier path - we need to modify structures on new business environment changes. However, this does not mean that we shall rewind ourselves back to the 60's, when all sub-regions of one country were having small warehouses. It just means that instead of one centralized location, companies do consider to have the second, third and possibly fourth warehouse to serve their needs [17].

This research work is structured as follows: In Section 2 methodological issues of five surveys conducted during years 2006-2012 is being reviewed. Thereafter, Section 3 analyses research results from transportation costs, transportation units used and geographical coverage of warehouses and size of warehouses (employment). We conclude our research work in Section 4, where also further research avenues are stated.

\section{Research Methodology}

The aim of this study is to use secondary data to illustrate warehousing importance, and primary data gathered through logistics survey during five occasions between years 2006-2012. Survey part of the research work was conducted by utilizing a web-based questionnaire, which was translated into English, Finnish and Swedish. The research sample was gathered from two leading economical magazines, Talouselämä from Finland and Affärsdata from Sweden. Both magazines gather TOP500 company listings, giving good base for our research (for the year 2012 survey Swedish list was a bit extended to take into account also some significant companies out of TOP500 list). We either sent survey form link to directly logistics director of these respective companies or in a case of not having direct contact, sent email to respective company's info address. Email addresses have been updated during the years with web search and own information from key decision maker changes.

As strategic information from logistics flows is difficult to obtain, we sent in each year initial contact email and in many cases three remainders (each respondent had own code in answering, further increasing reliability of our sample). Survey form in general has been kept as the same, having some 
minor changes due to contemporary events in logistics branch (e.g., influence of economic crisis on operations, pressure of environmental legislation on costs, small shipments, used transportation units etc.).

Table 2. Five surveys conducted, answers received and total contacts being made

Year All answers Valid answers Emails sent Response rate

\begin{tabular}{|r|r|r|r|r|}
\hline 2012 & 36 & 28 & 833 & $3.4 \%$ \\
\hline 2011 & 28 & 26 & 516 & $5.0 \%$ \\
\hline 2010 & 31 & 25 & 570 & $4.4 \%$ \\
\hline 2009 & 44 & 35 & 533 & $6.6 \%$ \\
\hline 2006 & 74 & 64 & 768 & $8.3 \%$ \\
\hline Total & 213 & 178 & 3,220 & \\
\hline
\end{tabular}

As not all companies listed in TOP500 lists do not have significant logistics flows at their disposal (e.g., financial, software, service, and insurance), the total sample was less than 1000 companies: During years 2009-2011 survey was sent roughly to 500 respondents (both Sweden and Finland together), while in the base year 2006 and most recent year we had more than 750 respondents. Response amounts have not been that great as in each year we have achieved below 10\% response rate (Table 2). Interestingly during first survey round we achieved approx. $8 \%$ response rate (maximum), and thereafter gradually declining to min. $3.4 \%$ in year 2012. However, absolute amount of answers have been above 25 , giving some confidence over the analysis results. In the last observation year we were able to increase absolute of amount answers, which is small positive surprise in the declining popularity of our longitudinal survey rounds.

Our sample is a somewhat biased to Finnish companies side, since during year 2006 approximately $70 \%$ of all answers came from Finland, and during year 2009 this share was at the level of $60 \%$. In year 2010 survey share of Finnish responses increased up to $72 \%$, but declined to the level of $60 \%$ in year 2011. As we a bit modified and extended the audience of year 2012 for most recent survey concerning Sweden, we received first time most of the answers form this country. Share of Finnish answers in the last round was just above $35 \%$.

Nearly all respondents were managers, white collar workers or directors that were having a long experience in the field of logistics. Typically respondents had been working in company for four years or more (approx. 80\%), and had long experience from logistics in general (highest frequency, more than half, at class of 8 years or more). Due to this our sample's reliability is strong. Furthermore, the fact that nearly same questionnaire was utilized in previous studies, confirms the survey's validity. We have also visited companies and have completed case studies during years 2006 and 2010. These site visits confirmed that our research area is valid, interesting, and used survey form applicable to its purpose.

\section{Survey Findings from Period of 2006-2012}

\section{Transportation Costs Estimates in Recent Year Surveys}

In earlier surveys (2006, 2009 and 2010) transportation costs (excluding warehousing) were typically either in medium class $(4-6 \%)$ or in the highest $(8-10 \%)$. However, during year 2011 survey highest frequency in answers was recorded in lowest transportation cost class (Figure 1). This could be caused anomaly arising from industrial sub-sectors or sales terms used, but what is interesting in year 2011 survey was that many companies were evaluating that their costs remained as the same. So, two lowest classes took above half from the frequency for the year 2017 estimate too. Even if most of the companies were arguing that their cost development was low and stabile - in some limited amount of companies it was opposite. During year 2011 on Figure 1 we could identify that share of two highest cost classes is nearly double in year 2012 and 2017 as compared to year 2009. It could be only guessed, why this sort of development occurs. One reason could be crisis year of 2009, when transportation costs declined heavily due to lack of demand and excessive capacity in the transportation sector overall. 


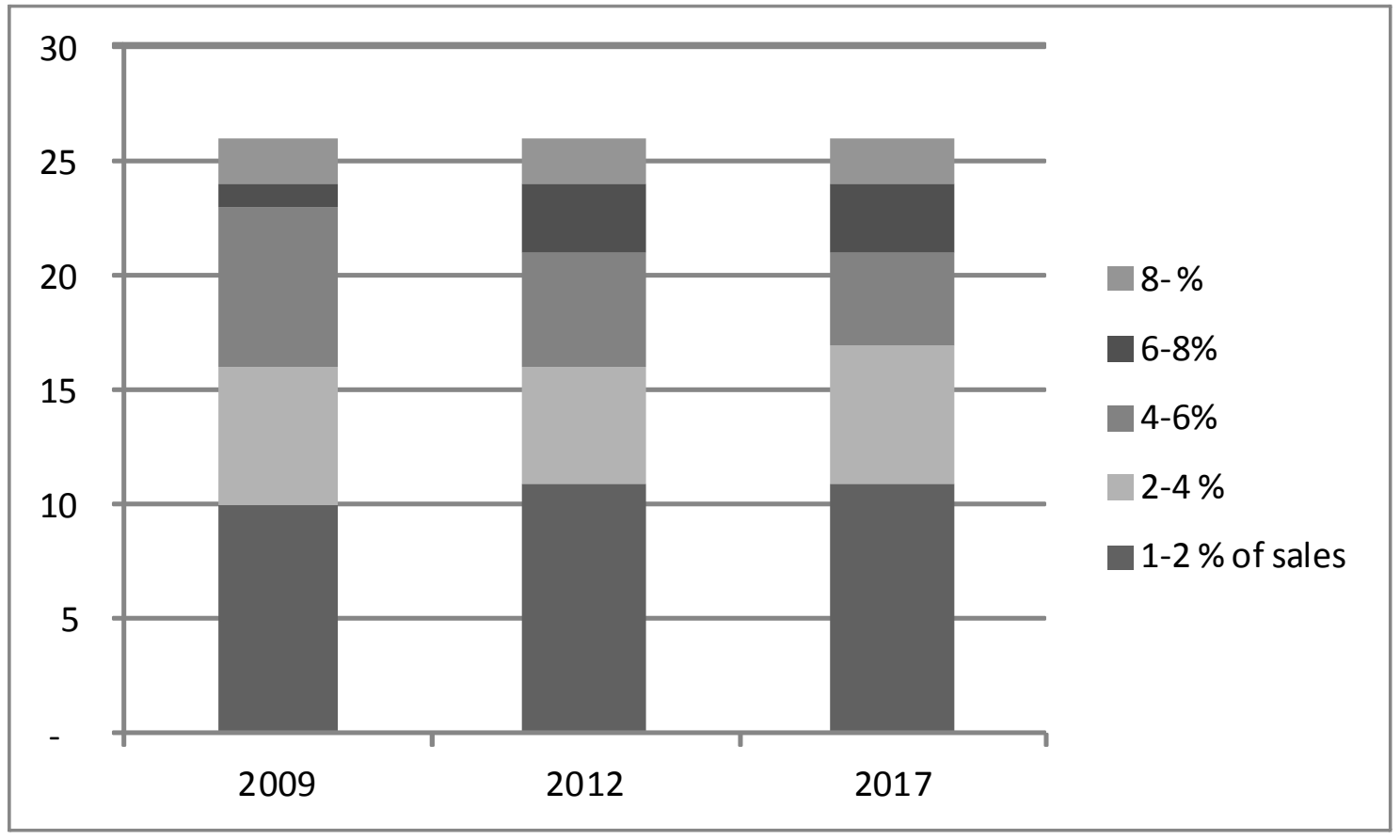

Figure 1. Companies estimate from simply transportation costs (excl. warehousing) during year 2011 survey $(\mathrm{n}=26)$

In most recent survey (year 2012) transportation cost picture has changed back what it was in the earlier surveys: Highest frequency is now in the middle class (4-6\%), followed closely by highest (more than $8 \%$ ) and lowest (1-2\%) classes. Again we may find similar polarization in the answers - group of 10-11 companies in all three years estimate that their costs are going to be low (two lowest classes). However, some companies are in turn reporting from increasing costs within the future (two highest classes).

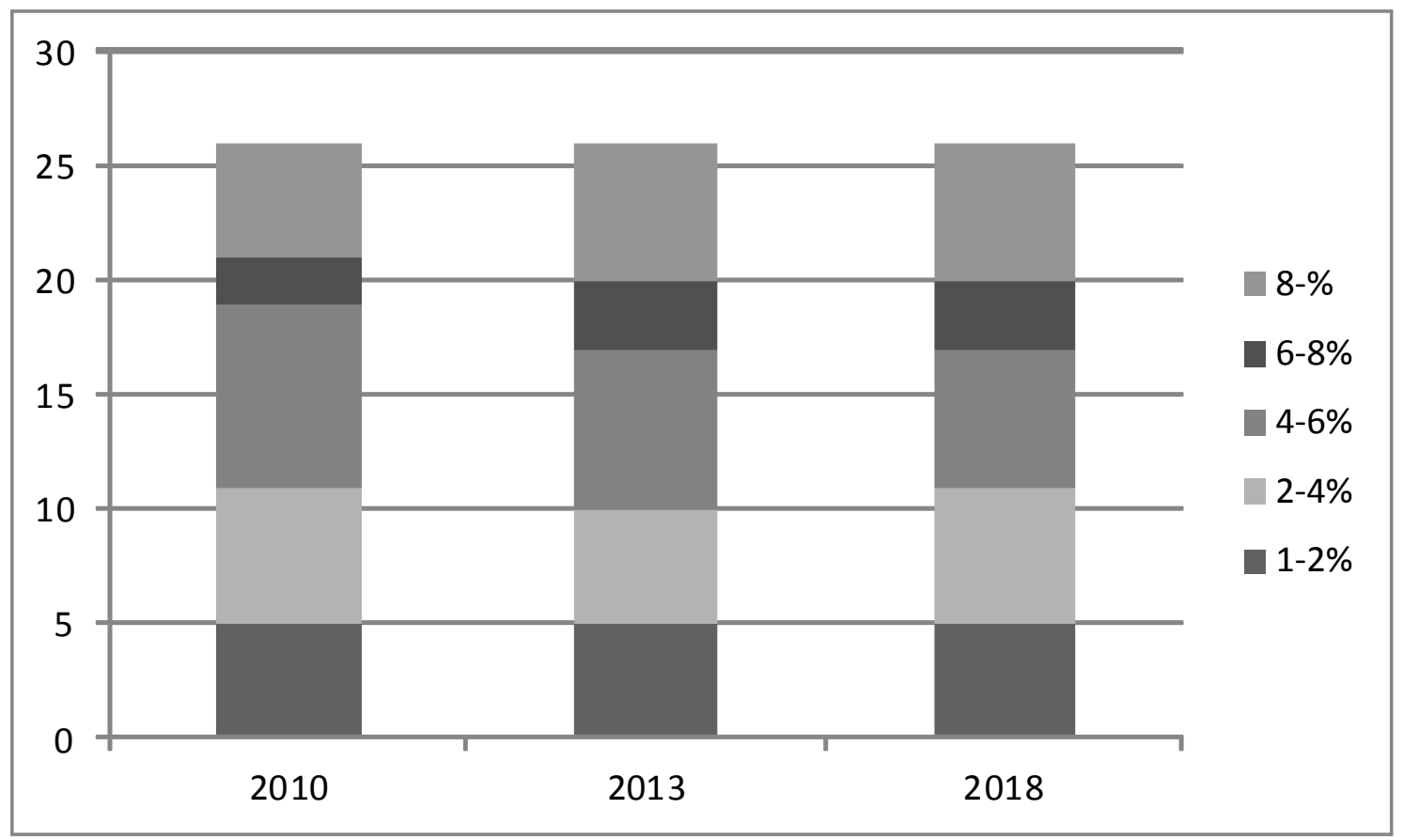

Figure 2. Companies estimate from simply transportation costs (excl. warehousing) during year 2012 survey $(n=26)$ 
Development in costs could be explained with number of different factors. For example, in most recent survey we asked from companies that will the new IMO/EU sulphur regulations increase the transportation costs (based on independent studies this increase will be $30-40 \%$ higher tariffs at Baltic Sea from year 2015 onwards; [18]). Not that surprisingly $78 \%$ of the companies responded that they will hurt and increase their transportation cost competitiveness. Similarly in year 2011 we had additional question from the effect of year 2009 credit crunch and individual company recovery out of it. Still one third from the companies responded that they have not fully recovered from recession. During year 2011 we also asked about taking into account environmental effects, while selecting transportation mode. Most of the companies $(77 \%)$ were claiming to take environment into account, which just further reveals that companies are following ongoing environmental regulation change (and possible additional user charges) on transport sector very closely.

From these two additional questions out of two most recent survey rounds we may say that for export oriented companies transportation costs from Northern Europe onwards will increase. Companies also realize this and are rather consistent in their opinions. So, they do not expect any improvements on legislation, in subsidies from government / EU or from rapid technological development (that e.g., sulphur could be taken out with low cost with scrubbers installed on ships). However, on the other hand many companies still in year 2011 felt that they have not recovered from crisis of year 2009 - this in the big picture of transportation demand will surely mean that growth of transport is not problem free issue within Northern Europe, and earlier trajectories are not necessarily kept. Therefore, this development will without a doubt be seen in transportation prices as downward pressure. Most probably this will mean better cost competitiveness for those companies, which are not import-export intensive.

\section{Used Transportation Units}

In recent decades globally we have been experiencing significant shift to unitised cargo, mostly leading to the increased use of containers. However, this movement started to catch countries of interest in this study within larger extent two decades ago. Up in north still today within short distance transport (e.g., from Sweden or Finland to Europe) most popular type of transportation unit is semi-trailer. Even if it is much more capital intensive (trailer will cost approx. 50000 euros as a new, while 40 feet container 3500 euros), and weights more, but companies have used to this container on wheels option, as it is flexible (strikes at container sea ports) and versatile. Also additional equipment is not needed in sea ports, if truck is put inside of sea vessel too. However, companies are often completing European shipments, e.g., in Finland in a manner that semi-trailer is left in sea port, from where terminal tractors take them inside of RoRo ship.

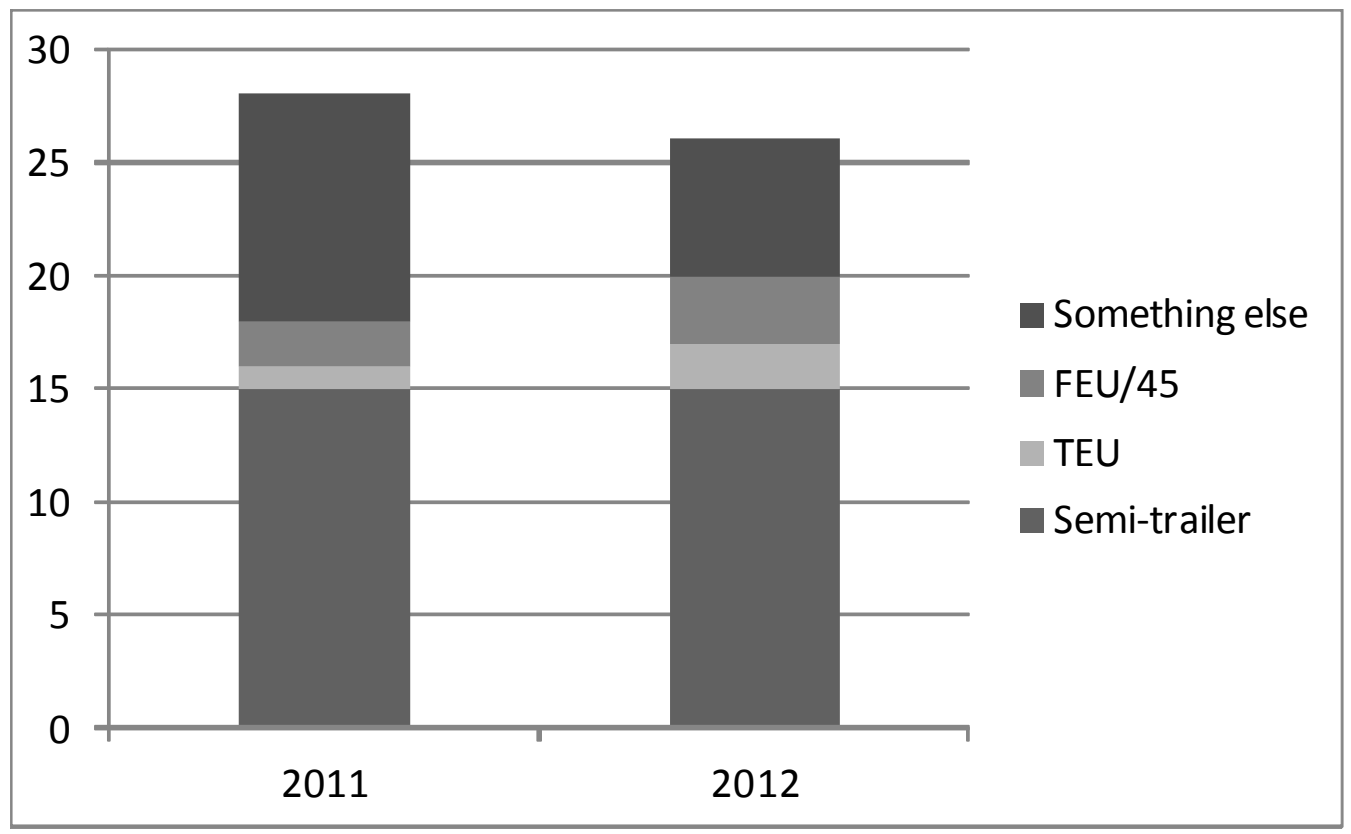

Figure 3. Use of transportation units in Northern Europe during years 2011 and 2012 (amount of absolute answers) 
Although, containers (on Figure 3, FEU and TEU) have sure advantage over semi-trailer, companies are still mostly favouring latter ones (more than $50 \%$ in both years). However, as encouraging small change is that both container types are a little bit increasing their popularity (still their share from overall responses in most recent year is slightly below $20 \%$ as it is roughly $10 \%$ during year 2011). This ought to improve reaching environmental objectives, as e.g., transporting container on rail is much lower weight than putting semi-trailer wagon on railway wagon. Also otherwise e.g., RoRo ships (main sea transport mode for semi-trailers) are more environmentally unfriendly than container vessels. Containers should have platform for further growth as most of the long-distance trade (e.g., Asian and North American trade) is completed with these, and they are in large numbers available to be used in transportation within Northern Europe. Readers should note that mixture of answers in country level was totally different in years 2011 and 2012 - so in other words semi-trailers are not popular only in Finland, but in Sweden, too.

\section{Location of Warehouses in Europe}

Each year we have been asking from the companies about their European warehouses (not only European Union, but whole geographical Europe, incl. also e.g., Russia, Byelorussia, Turkey and Norway). Surprisingly companies do have number of warehouses in Europe, and they do not distribute products only from one location (which could be one most probable path due to higher economical integration in Europe). What is striking in the answers, is the role of the Baltic Sea Region countries (incl. also Norway) - as Table 3 shows Finnish and Swedish companies are having most of their warehouses in this region. Relative share variates during the years, but is between 60-70\% during period of 2006-2011. In most recent survey (year 2012) this trend is broken due to Finnish answers, and total amount drops to just above $40 \%$. Reasons for this drop could be just based on low amount of Finnish answers, but also due to the reason that economic situation has remained as challenging, e.g., in the Baltic States (GDP contracted in these three countries during year 2009 by $15-19 \%$, and has not still increased to pre-crisis level). We have even evidence from this sort of change in our longitudinal data. During year 2006 Finnish and Swedish companies argued that they have 51 warehouses in Poland and the Baltic States, while in year 2012 this have dropped to five (in relative amount this drop has been from $20 \%$ to just above $3 \%$ ). This reduction has been ongoing during the years, and particularly so among Finnish respondents.

Table 3. Warehouses of Finnish and Swedish companies in Europe - role of Baltic Sea Region

Warehouses in the Baltic Sea Region
\begin{tabular}{|l|r|r|r|r|r|r|}
\hline Finland & 2006 & $\mathbf{2 0 0 9}$ & $\mathbf{2 0 1 0}$ & $\mathbf{2 0 1 1}$ & $\mathbf{2 0 1 2}$ \\
\hline Sweden & 116 & 68 & 45 & 31 & 32 \\
\hline Total & 55 & 20 & 19 & 26 & 31 \\
\hline
\end{tabular}

\begin{tabular}{|l|r|r|r|r|r|}
\hline Finland & $75.3 \%$ & $63.6 \%$ & $77.6 \%$ & $79.5 \%$ & $30.2 \%$ \\
\hline Sweden & $56.7 \%$ & $47.6 \%$ & $55.9 \%$ & $60.5 \%$ & $67.4 \%$ \\
\hline Total & $68.1 \%$ & $59.1 \%$ & $69.6 \%$ & $69.5 \%$ & $41.4 \%$ \\
\hline
\end{tabular}

Warehouses in Europe

\begin{tabular}{|l|r|r|r|r|r|}
\hline Finland & 154 & 107 & 58 & 39 & 106 \\
\hline Sweden & 97 & 42 & 34 & 43 & 46 \\
\hline Total & 251 & 149 & 92 & 82 & 152 \\
\hline
\end{tabular}




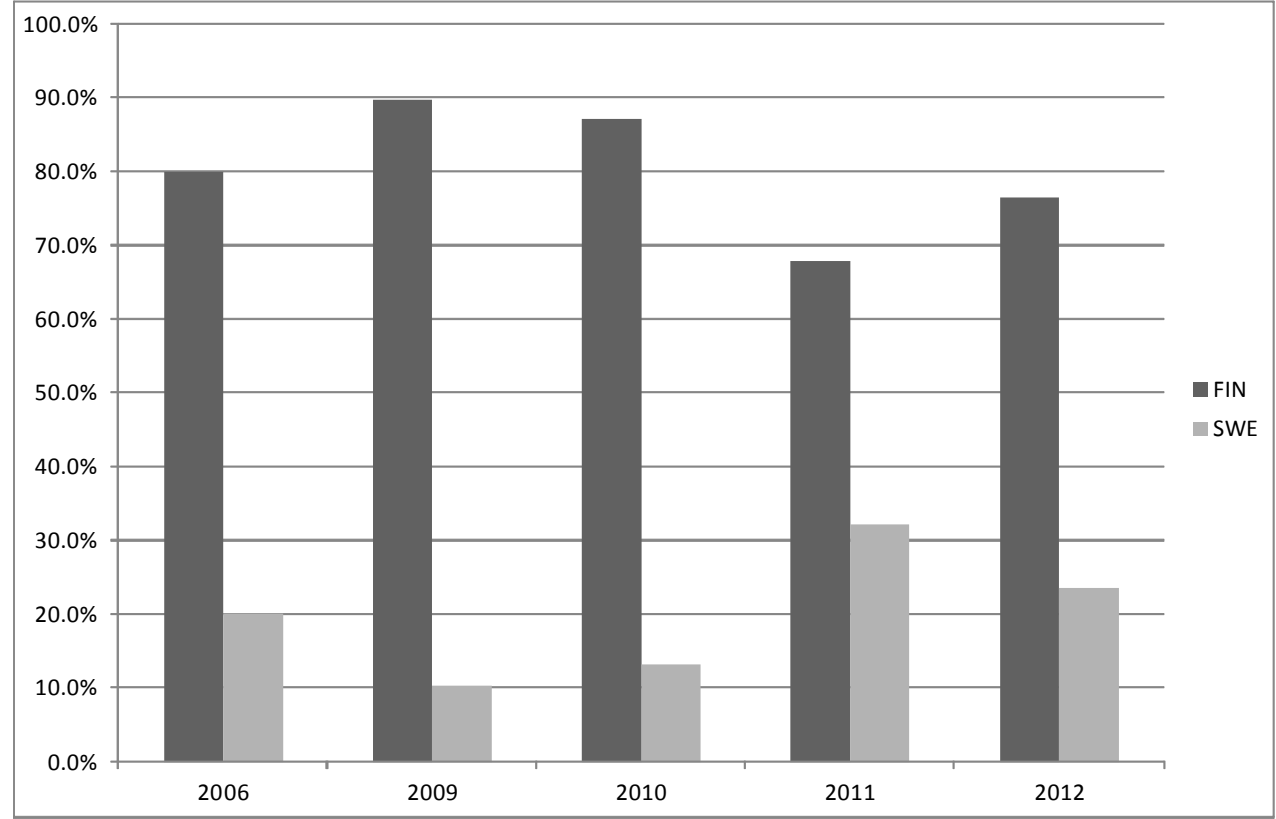

Figure 4. Share of warehouses in Central and Eastern European Countries (CEEC) during observation period in each year among Finnish and Swedish respondents

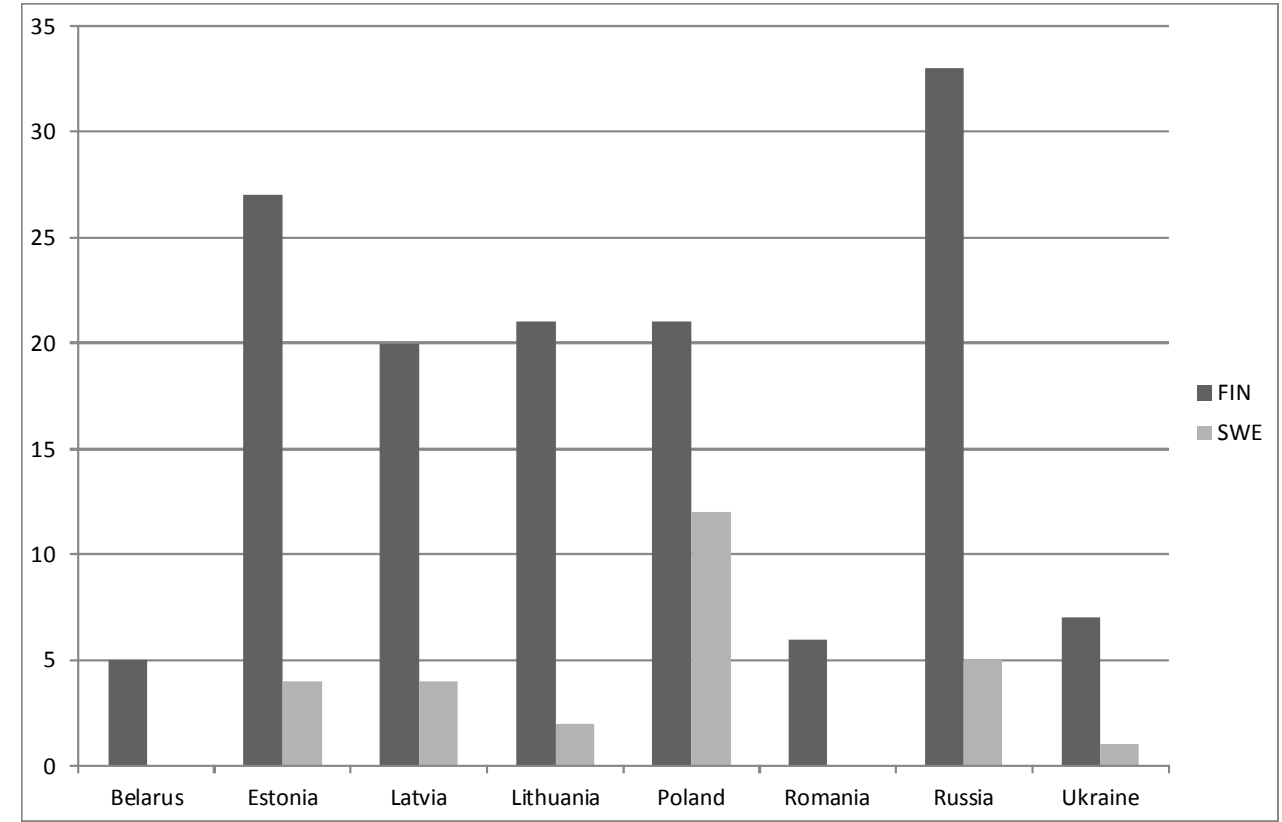

Figure 5. Total number of warehouses (absolute) in five selected Central and Eastern European Countries (CEEC) during observation period (five surveys) among Finnish and Swedish respondents

Figures 4 and 5 illustrate situation further. Typically Finnish companies are much more active in warehousing (and sales thereof) to more risky European markets, CEEC (Figure 3). Difference was of course wider, when warehouses in the Baltic States and Poland were at record levels, but still in year 2012 difference between Finland and Sweden is very much present (should be noted that Finnish answers to survey were lower than Swedish ones in the last observation year, while earlier Finnish answers have dominated the responses). Finland is much more active still in Russian markets, and in Byelorussia (Figure 5).

\section{Employment in Warehouses}

Like in earlier years of the survey completion, years 2011 and 2012 repeated the same already identified pattern: Both small and large warehouses are present in the future too, however, with the small tendency, 
where larger warehouses are about to be more popular in the future. Change for larger is not that much apparent on Figure 6 (year 2011 findings), but is more so on Figure 7. Interestingly in most recent survey, change is from second largest class to the largest one. Also worth to notice is the continuing existence of very small warehouses - these most probably due to the volume differences and markets being served. For example, company could concentrate only on the Baltic States or Russia with its manufacturing export, and then warehouses are at typical small ones and overall volumes remain low (in target regions).

As reported earlier, we asked from companies in year 2012 survey separately from the emerging market warehouses outside of European continent. In total 13 responses were gained from companies, and most of the argued to use small units in their warehousing activity in distant location. For the future this situation will remain very much as the same, but with distinction that small shift is possible from second lowest class to middle sized warehouse.

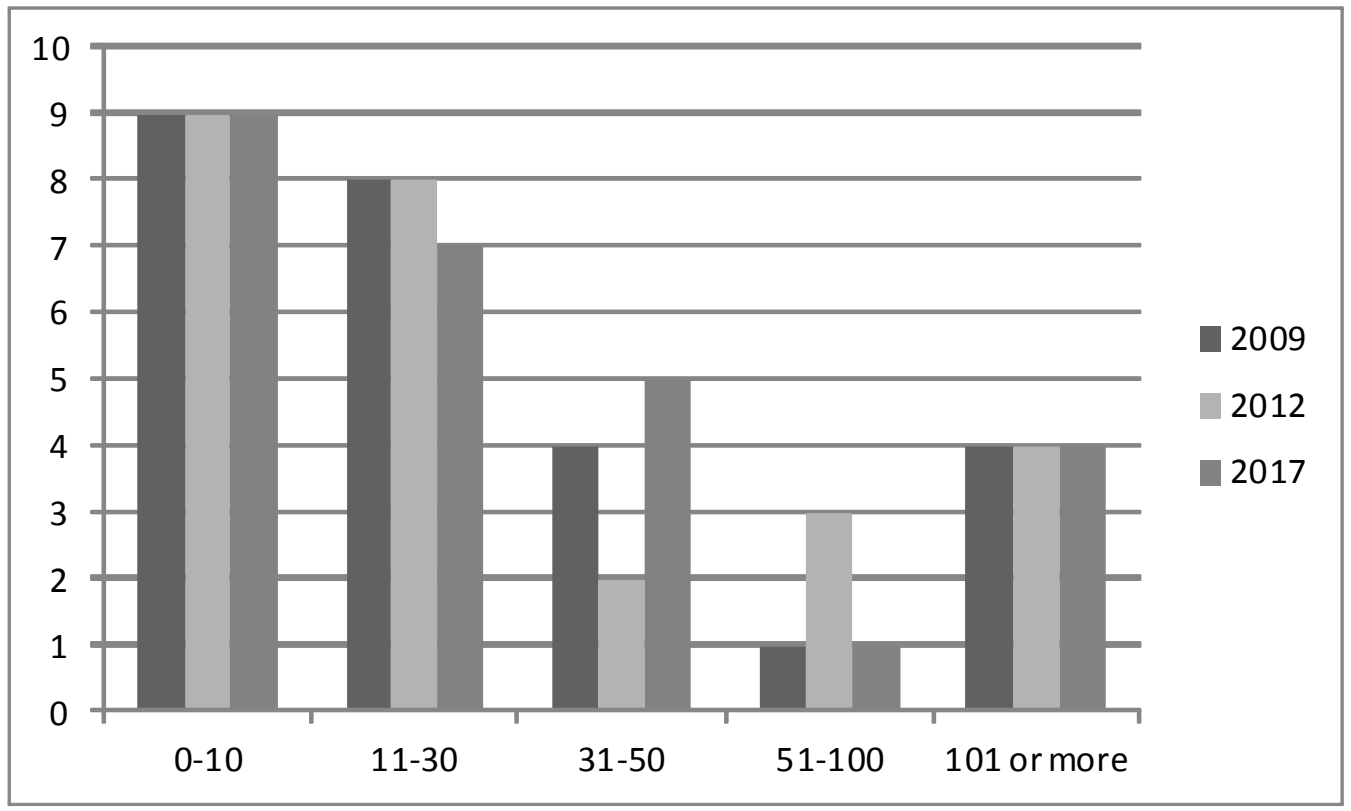

Figure 6. Frequency distribution of the employment (size) of warehouses concerning both countries using year 2011 responses $(n=26)$

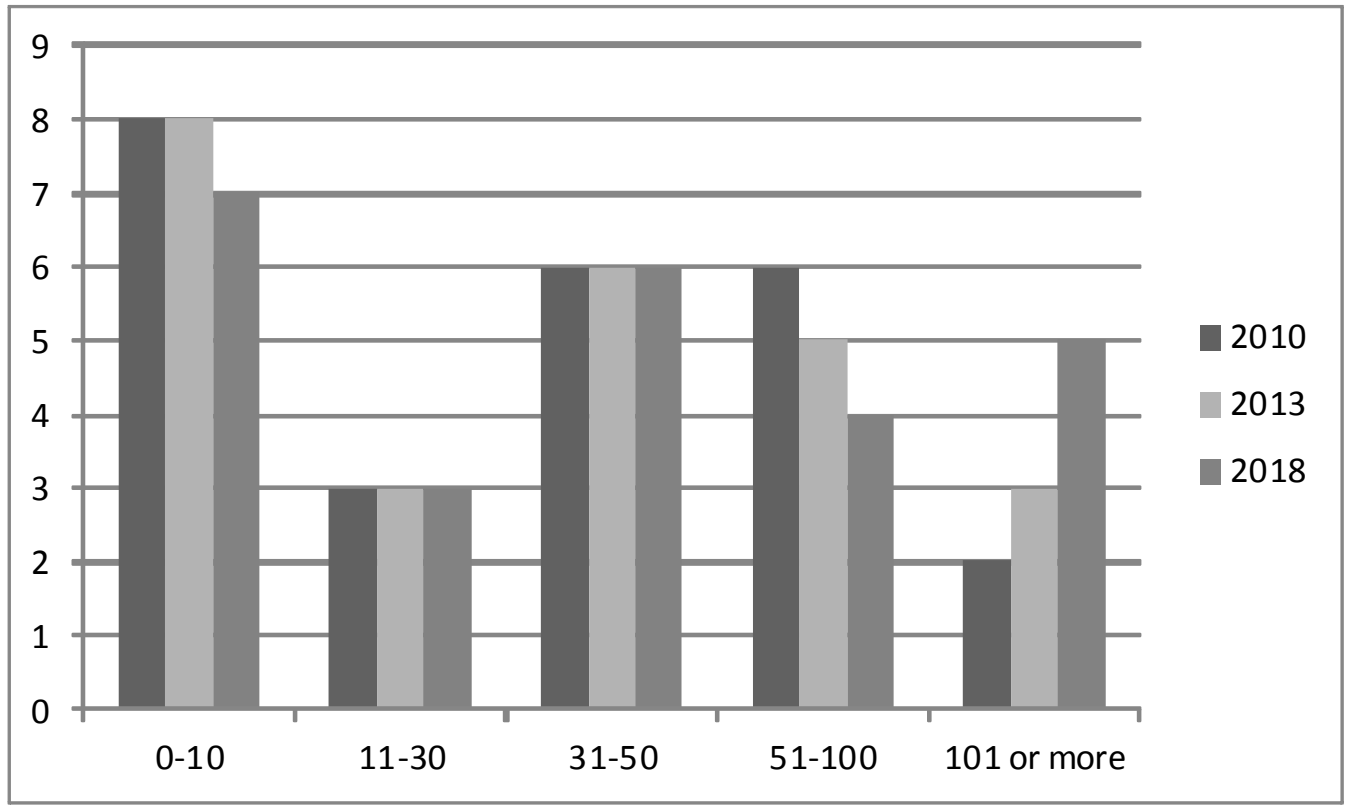

Figure 7. Frequency distribution of the employment (size) of warehouses in Europe concerning both countries using year 2012 responses $(n=25)$ 
In light of these answers, it could be concluded that drastic improvements in productivity of warehousing work are not at sight - these typically are completed with larger units, higher volume and automation investments. It is of course known fact that entirely centralized (e.g., one European warehouse) will lead to massive amount of transportation, particularly road. However, a bit more decentralized structure (e.g., three to four European warehouses) will considerably decrease transportation activity ([17] talk about reforming regional distribution centres). It is understandable that companies are not keen to centralize and make warehouses larger units in current environment, where oil prices have sustained their high levels, and in future we have additional environmental payment burden coming in terms of $\mathrm{CO}_{2}$ emission payments.

\section{Conclusions}

Warehousing holds significant importance on the employment of European Union, and most of the working places are not included in the statistics of the region wide records. Currently warehousing is following on transportation sector statistics road transports (freight), but it could be assumed that it is at same level or even higher as in-house completed activities, e.g., at retail and manufacturing are taken into account (which is not currently the situation). However, based on our research findings, environment has not that greatly changed in warehousing front in Finnish and Swedish companies (e.g., size of them in terms of employment remains as the same or slightly increases). We could state that costs remain in the same level or to slightly increase in the future. This even in the post 2009 economic crisis world, where transportation logistics sector is not having prosperous future insight in North European countries. Also transportation logistics practices are not that greatly changing: Still dominant transportation device is semi-trailer. However, in positive light could be reported that containers are taking some more share in most recent survey round. In all survey rounds we also were able to identify that short-distance, basically Baltic Sea Region countries, attract most of the warehousing placement in larger European context. This is interesting finding as, e.g., the Baltic States and Poland have been for years in the same trade area together with other EU countries. Some evidence is that the Baltic States warehousing is among Finnish company responses on decline, together with finding that weight is transferred from BSR to elsewhere in Europe. However, this argumentation arises from most recent survey round, and has only limited amount of answers. In longitudinal perspective we were able to show that Finnish companies are much better placed within CEEC distribution than Swedish counterparts.

As a further research natural step to be taken would be completion of this survey during year 2013. Together with this we would be interested from warehousing change after economic hardship started in year 2009. Effects are still ongoing in European business practices, and would be extremely interesting to examine, how uncertainty and possible declines in sales are taken into account. Environmental issues and their role in this new demanding business environment would be interesting to study, too, maybe simultaneously with operating models in post 2009 era.

\section{References}

1. Edgell, Jon, Gabriel, E. Meister \& Nigel Stamp. (2008). Global outsourcing trends in 2008. Strategic Outsourcing: An International Journal, 1(2), 173-180.

2. Tian, Yu, Fujun Lai \& Francis Daniel. (2008). An examination of the nature of trust in logistics outsourcing relationship - empirical evidence from China. Industrial Management \& Data Systems, 108(3), 346-367.

3. Cap Gemini. (2007). 2007 Third-Party Logistics - Results and Findings from $12^{\text {th }}$ Annual Study. Retrieved February 6, 2008, from http://www.de.capgemini.com/m/de/tl/Third-Party_Logistics_2007.pdf.

4. Hilmola, Olli-Pekka \& Albert Wee Kwan Tan. (2010). Logistics outsourcing and supply management in Finland, Sweden and UAE. International Journal of Procurement Management, 3(1), 32-53.

5. Solakivi, T., Ojala, L., Töyli, J., Hälinen, H-M., Lorentz, H., Rantasila, K., Huolila, K. \& Laari, S. (2010). Finland State of Logistics 2010. Helsinki, Finland: The Ministry of Transportation and Communications. (In Finnish).

6. European Union. (2011). EU Transport in Figures - Statistical Pocketbook 2011. Luxemburg: Publications Office of EU.

7. European Union. (2012). EU Transport in Figures - Statistical Pocketbook 2012. Luxemburg: Publications Office of EU. 
8. Maister, D. H. (1976). Centralization of inventories and the square root law. International Journal of Physical Distribution and Materials Management, 6(3), 124-134.

9. Seppälä, Ulla. (1997). An Evolutionary Approach for Location Economic Facilities. Acta Polytechnica Scandinavica, Mathematics, Computing, and Management in Engineering Series, No. 83 (Doctoral dissertation). Helsinki, Finland: Helsinki University of Technology.

10. Das, Chandrasekhar \& Rajesh Tyagi. (1999). Effect of correlated demands on safety stock centralization: Patterns of correlation versus degree of centralization. Journal of Business Logistics, 20(1), 205-213.

11. Duan, P. (2006). An Integrated Modeling Framefork for Intermodal Freight Operations Hub Cities. Doctoral Dissertation. USA: North-western University.

12. Hilletofth, Per, Olli-Pekka Hilmola \& Frida Claesson. (2011). In-transit Distribution Strategy: Solution for European Factory Competitiveness? Industrial Management and Data Systems, 111(1), 20-40.

13. Pagh, J. D. \& Cooper, M. C. (1998). Supply chain postponement and speculation strategies: how to choose the right strategy. Journal of Business Logistics, 19(2), 13-33.

14. Hilletofth, Per. (2009). How to develop a differentiated supply chain strategy? Industrial Management \& Data Systems, 109(1), 16-33.

15. Baker, Peter. (2007). An exploratory framework of the role of inventory and warehousing in international supply chains. International Journal of Logistics Management, 18(1), 64-80.

16. Hilletofth, Per, Eriksson, David \& Olli-Pekka Hilmola. (2012). Two sides of a token: Coordinating demand and supply at furniture wholesaler. International Journal of Manufacturing Research, 7(2), 101-122.

17. Simchi-Levi, David, Peruvankal, James Paul, Mulani, Narendra, Read, Bill \& John Ferreira. (2012). Is it time to rethink your manufacturing strategy? Sloan Management Review, 53(2), 20-22.

18. Kalli Juha, Karvonen, Tapio \& Teemu Makkonen. (2009). Sulphur Content in Ships Bunker fuel in 2015: A Study on the Impacts of the new IMO Regulations and Transportation Costs, No. 31. Helsinki, Finland: Ministry of Transport and Communications.

19. Kabashkin, Igor. (2012). Freight transport logistics in the Baltic Sea Region. Regional aspects. Transport and Telecommunications, 13(1), 33-50.

20. Baker, Peter \& Jon Sleeman. (2011). The impact of economic and supply chain trends on British warehousing. In Conference Proceedings on Logistics Research Network, 2011. Southampton, UK. (CD-ROM)

21. Ashayeri, Jalal \& Joost M. J. Rongen. (1997). Central distribution in Europe: A multi-criteria approach to location selection. International Journal of Logistics Management, 8(1), 97-109. 